\section{A) Check for updates}

Cite this: Org. Chem. Front., 2017, 4 1058

Received 8th August 2016 Accepted 13th February 2017

DOI: $10.1039 / c 6 q 000448 b$

rsc.li/frontiers-organic

\title{
Reaction-based indicator displacement assay (RIA) for the colorimetric and fluorometric detection of hydrogen peroxide $\dagger$
}

\author{
Xiaolong Sun, ${ }^{* a}$ Maria L. Odyniec, ${ }^{a}$ Adam C. Sedgwick, ${ }^{a}$ Karel Lacina, ${ }^{a, b}$ Suying Xu, ${ }^{c}$ \\ Taotao Qiang, ${ }^{d}$ Steven D. Bull, ${ }^{a}$ Frank Marken ${ }^{a}$ and Tony D. James ${ }^{{ }^{a}}$
}

Based on the complexation of phenylboronic acid (PBA) with Alizarin Red S (ARS), we developed a new chemosensor for the detection of hydrogen peroxide $\left(\mathrm{H}_{2} \mathrm{O}_{2}\right)$ in aqueous media. This platform has demonstrated its ability to detect $\mathrm{H}_{2} \mathrm{O}_{2}$ via colorimetric, fluorometric, and electrochemical measurements. The experimental observations reveal that the system displays a red-shifted visible colour change, on-off fluorescence response indicating release of indicator (ARS) and turn-on electrochemical signal indicating generation of phenol, after reaction with $\mathrm{H}_{2} \mathrm{O}_{2}$. With this work we have demonstrated that our reaction-based indicator displacement assay (RIA) systems, can be employed as an assay for $\mathrm{H}_{2} \mathrm{O}_{2}$ and hydrogen peroxide-related species for environmental and physiological detection.

\section{Introduction}

Hydrogen peroxide $\left(\mathrm{H}_{2} \mathrm{O}_{2}\right)$ was first described in 1818 by Louis Jacques Thénard, who produced it by treating barium peroxide with nitric acid. ${ }^{1}$ It is the simplest peroxide with an oxygenoxygen single bond and is a strong oxidant, which has been widely used as a bleaching agent and disinfectant, such as fabric stain removers, leather-making, contact lens disinfectants and hair dyes., ${ }^{2,3}$ In biological and physiological processes, $\mathrm{H}_{2} \mathrm{O}_{2}$ is an essential oxygen metabolite in living systems, with mounting evidence supporting its role as a messenger in cellular signal transduction. ${ }^{4}$ In particular, $\mathrm{H}_{2} \mathrm{O}_{2}$, as one of the reactive oxygen species (ROS), has important roles as a signalling molecule in the regulation of a wide variety of biological processes, such as immune response, cell signalling, ${ }^{5}$ Alzheimer's diseases ${ }^{6}$ and cancer. ${ }^{7}$ Thus, chemical and biological sensing of $\mathrm{H}_{2} \mathrm{O}_{2}$ in vivo and in vitro has drawn much attention over the past decades.

Among the powerful tools available for $\mathrm{H}_{2} \mathrm{O}_{2}$ detection are synthetic small-molecular fluorescent probes owing to their

${ }^{a}$ Department of Chemistry, University of Bath, BA2 7AY, UK.

E-mail: Xiaolong.sun86@gmail.com,T.D.James@bath.ac.uk

${ }^{b}$ CEITEC, Masaryk University, Kamenice 5, 62500 Brno, Czech Republic

${ }^{c}$ Department of Analytical Chemistry, Faculty of Science, Beijing University of

Chemical and Technology, Beijing, 100029, China

${ }^{d}$ College of Light Industry Science and Engineering, Shaanxi University of Science and Technology, Xi'an, 710021, China

$\dagger$ Electronic supplementary information (ESI) available: General methods, methods used for ROS generation and UV and fluorescence spectra. See DOI: 10.1039/c6qo00448b high sensitivity, simple manipulation and easy instrumentation. We have a long-standing interest in boronic acids for monosaccharide and anion detection. ${ }^{8-10}$ Previously, we also investigated the use of "integrated" and "insulated" boronatebased fluorescent complexes for the detection of $\mathrm{H}_{2} \mathrm{O}_{2}\left(\mathrm{p} K_{\mathrm{a}}=\right.$ 11.6). ${ }^{11,12}$ In addition, Chang and co-workers have developed a series of boronate-based derivatives for the fluorescence detection of $\mathrm{H}_{2} \mathrm{O}_{2}$ in living systems. ${ }^{13-23}$ Therefore, we were inspired to explore and develop more boronic acid based systems for detection of $\mathrm{H}_{2} \mathrm{O}_{2}$ (Scheme 1).

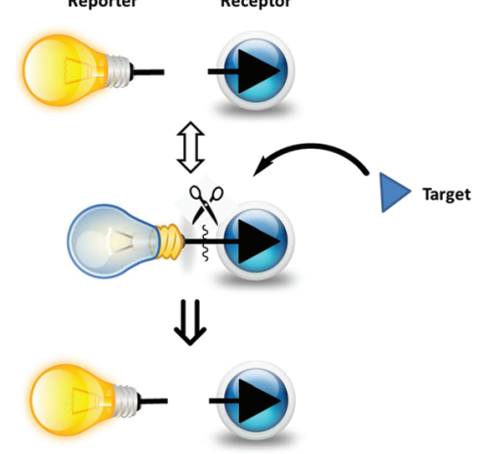

Scheme 1 Schematic illustration of the proposed RIA. Firstly: reversible interaction of receptor and reporter. Secondly: the receptor and reporter are selectively cleaved by a chemical reaction triggered by the target (analyte). The change of the output signal for the RIA system can then be used to detect the target. 
In terms of design of fluorescent probes, specifically our strategy for the detection of $\mathrm{H}_{2} \mathrm{O}_{2}$ is based on the construction of a reporter-receptor framework through reversible covalent bonding (Scheme 1). Alizarin Red S (ARS) has been successfully employed as a general optical reporter for various studies, such as binding ability of boronic acids with carbohydrates. ${ }^{24,25}$ Binding with boronic acids derivatives, ARS showed a visible colour change (from purple to orange) and an increase in fluorescence intensity due to the inhibition of proton-induced fluorescence quenching (Scheme 2). ${ }^{26}$ Also, our previous research has demonstrated the binding and analyte-mediated release of ARS with hydrogel-bound boronic acid. $^{27}$ Notably, the use of surfactants by Ngeontae et al. improved the sensitivity of glucose sensors developed using alizarin-boronic acid adducts. ${ }^{28}$

Bearing these results in mind, we decided to evaluate the sensing system, ARS-PBA complex, that was formed by the attachment of phenylboronic acid with Alizarin Red S in situ (Scheme 2), assembled with the assistance of cetyl trimethylammonium bromide (CTAB) for the detection of $\mathrm{H}_{2} \mathrm{O}_{2}$ in an aqueous environment. It was demonstrated that the sensing system displays good colorimetric, fluorometric and electrochemical response towards $\mathrm{H}_{2} \mathrm{O}_{2}$ in neutral aqueous buffer. The oxidation between boronic ester and $\mathrm{H}_{2} \mathrm{O}_{2}$, which lead to the release of ARS and generation of phenol can be detected optically through a colour change. Meanwhile, significant fluorescence changes indicate that the methodology could be potentially used for biologically cell imaging and endogenous detection of $\mathrm{H}_{2} \mathrm{O}_{2}$. Therefore, this representative system can be extended to new applications for the study of other reactive oxygen and nitrogen species (ROS and RNS), using a Reactionbased Indicator displacement Assay (RIA) (Scheme 1). ${ }^{29}$ We have previously demonstrated the RIA concept using ARS with 2-(N,N-dimethylaminomethyl) phenylboronic acid (NBA) which can be used to selectively detect peroxynitrite using the neighbouring nitrogen of NBA to protect the boron and facilitate ARS complexation without the need to add CTAB. The current

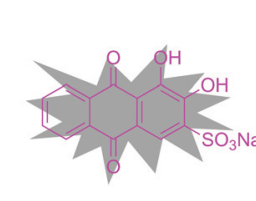

ARS, Weak FL, Purple
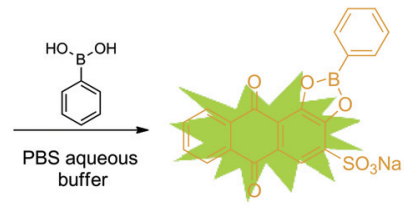

ARS-BA, Strong FL, Orange $\mathrm{H}_{2} \mathrm{O}_{2}$
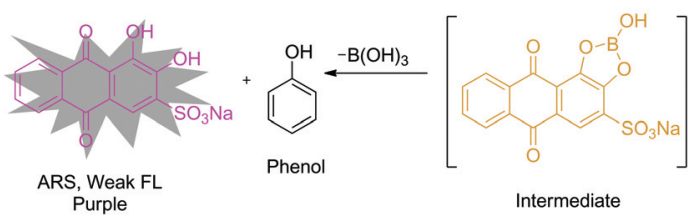

Scheme 2 Design strategy of probe ARS-PBA complex for the detection of hydrogen peroxide in neutral aqueous buffer with added CTAB. system shows how we can generalise the RIA concept to any boronic acid by means of CTAB to facilitate complexation and assembly of the RIA system.

\section{Experimental}

\subsection{Solvents and reagents}

Solvents and reagents were HPLC or reagent grade unless stated otherwise and were purchased from Fisher Scientific UK, Frontier Scientific Europe Ltd, TCI UK, and Sigma-Aldrich Company Ltd and were used without further purification.

\subsection{UV-Vis measurements}

UV-Vis measurements were performed on Perkin-Elmer Spectrophotometers. Absorption, utilising Starna Silica (quartz) cuvette with $10 \mathrm{~mm}$ path lengths, two faces polished. Data was collected via the Perkin-Elmer Lambda 20 software package.

\subsection{Fluorescence measurements}

Fluorescence measurements were performed on a PerkinElmer Luminescence Spectrophotometer LS 50B and Gilden Photonics Ltd. FluoroSENS, utilising LB UV4 FACES MACRO CUVETTE PMMA with $10 \mathrm{~mm}$ path lengths, four faces polished. Data was collected via the Perkin-Elmer FL Winlab software package.

\subsection{Electrochemical measurements}

Electrochemical measurements were performed on a $\mu$-Autolab potentiostat, Metrohm Autolab B.V. Carbon $(3 \mathrm{~mm}$ ) and gold (2 $\mathrm{mm}$ ) disc electrodes were used as working and auxiliary electrodes, respectively. Saturated calomel electrode was used as reference. Square wave voltammetry (SWV) with frequency 8.3 $\mathrm{Hz}$, potential step $4.95 \mathrm{mV}$ and amplitude $10.05 \mathrm{mV}$ was used. Working electrode was polished with alumina slurry $(0.3 \mu \mathrm{m})$ and rinsed with distilled water before each scan.

\subsection{Experimental procedure}

In the corresponding experiments, UV-Vis absorbance and fluorescence titrations with $\mathrm{H}_{2} \mathrm{O}_{2}$ were carried out at $25^{\circ} \mathrm{C}$ in pH 7.30 PBS buffer $\left(\mathrm{KH}_{2} \mathrm{PO}_{4}, 1 / 15 \mathrm{M} ; \mathrm{Na}_{2} \mathrm{HPO}_{4}, 1 / 15 \mathrm{M}\right)$ with $2.0 \mathrm{mM}$ cetyl trimethylammonium bromide (CTAB) and electrochemical data was obtained in $\mathrm{pH} 7.30$ buffer $(\mathrm{KCl}$, $0.1 \mathrm{M}, \mathrm{KH}_{2} \mathrm{PO}_{4}, 1 / 15 \mathrm{M} ; \mathrm{Na}_{2} \mathrm{HPO}_{4}, 1 / 15 \mathrm{M}$ ). The ARS-PBA complexes were formed by mixing free ARS $(50 \mu \mathrm{M})$ with phenylboronic acid $(200 \mu \mathrm{M})$ in situ.

\section{Results and discussion}

\subsection{UV-Vis measurements with $\mathrm{H}_{2} \mathrm{O}_{2}$}

Initially, in the UV-Vis spectroscopy, we observed that the maximum absorbance of free ARS $(50 \mu \mathrm{M})$ was centred at $\lambda_{\text {abs }}$ $=550 \mathrm{~nm}$ while addition of phenylboronic acid $(200 \mu \mathrm{M})$ caused a blue shift to $\lambda_{\mathrm{abs}}=480 \mathrm{~nm}$ which was attributed to 

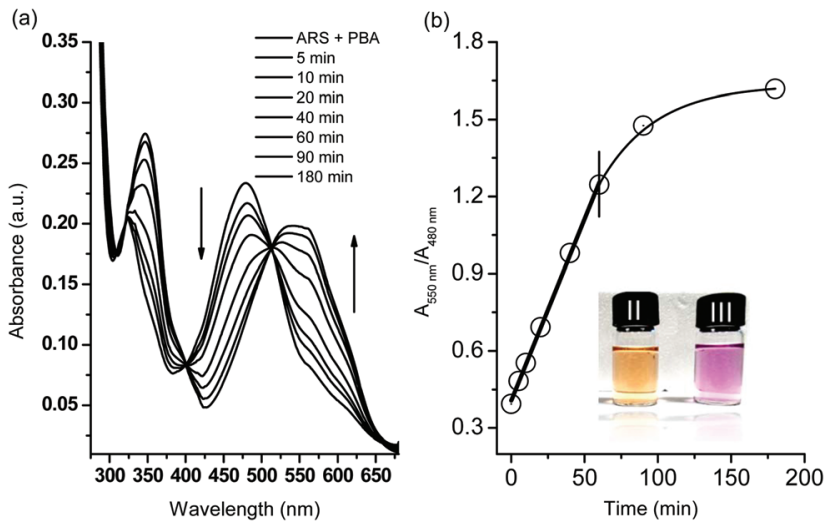

Fig. 1 (a) UV-Vis absorption spectra for ARS only $(50 \mu \mathrm{M})$, ARS-PBA (ARS, $50 \mu \mathrm{M}$; PBA, $200 \mu \mathrm{M})$ and then addition of $\mathrm{H}_{2} \mathrm{O}_{2}(500 \mu \mathrm{M}, 5,10,20$, $40,60,90,180 \mathrm{~min}$ ). (b) The data was obtained in 1/15 M PBS buffer with $2.0 \mathrm{mM} \mathrm{CTAB}$ in solution at $25^{\circ} \mathrm{C}$.

the conjugated structure formed in $\mathrm{pH} 7.30$ PBS buffer (Scheme 1 and Fig. S1 $\dagger$ ). Therefore, the boronic ester formation of ARS with PBS led to a significant colour change from purple to orange over $15 \mathrm{~min}$.

The $\mathrm{H}_{2} \mathrm{O}_{2}$-mediated oxidation of aryl boronate to phenol and subsequent decomposition of the intermediate induced release of ARS from the complex resulting in the recovery of the free ARS absorption. From Fig. 1a, when $\mathrm{H}_{2} \mathrm{O}_{2}(500 \mu \mathrm{M})$ was added to a solution of ARS-PBA complex (ARS, $50 \mu \mathrm{M}$; PBA, $200 \mu \mathrm{M}$ ), a significant decrease in the $480 \mathrm{~nm}$ absorbance was observed with the appearance of a red-shifted band centred at $550 \mathrm{~nm}$ over through $3 \mathrm{~h}$ with $2.0 \mathrm{mM} \mathrm{CTAB}$ in the system and a clear iso-absorbance point can be seen at $510 \mathrm{~nm}$. As can be seen from Fig. 1b, there is a good linear relationship between the absorption ratio $\left(A_{550 \mathrm{~nm}} / A_{480 \mathrm{~nm}}\right)$ and reaction time $(0-60 \mathrm{~min})$ at an initial concentration of ARSPBA $(50 \mu \mathrm{M})$ and $\mathrm{H}_{2} \mathrm{O}_{2}(500 \mu \mathrm{M})$. However, the recovered absorption intensity from the complex probe is only $86.9 \%$ of the original free ARS over a prolonged time, probably due to incomplete reaction or incomplete decomposition of the intermediate. Importantly, the absorption wavelength shift is a reflection of the colour change (from orange to purple over $60 \mathrm{~min}$ ) which can be readily visualised by the naked-eye (Fig. 1a). More importantly, ratiometric absorbance changes increase the dynamic range and permit signal-rationing, thus they provide a built-in correction for monitoring of environmental effects. ${ }^{30,31}$

\subsection{Emission measurements with $\mathrm{H}_{2} \mathrm{O}_{2}$}

In terms of emission spectroscopy, the fluorescence of free ARS $(50 \mu \mathrm{M})$ is quenched due to the active protons of the hydroxyanthraquinone (Fig. 2a), while the addition of various concentrations of phenylboronic acid causes a dramatic fluorescence intensity increase through the binding of the catechol unit of ARS with the boronic acid moiety (Fig. S2†). The formed complex was then used as part of a new fluorescence sensing system with a very strong emission properties.
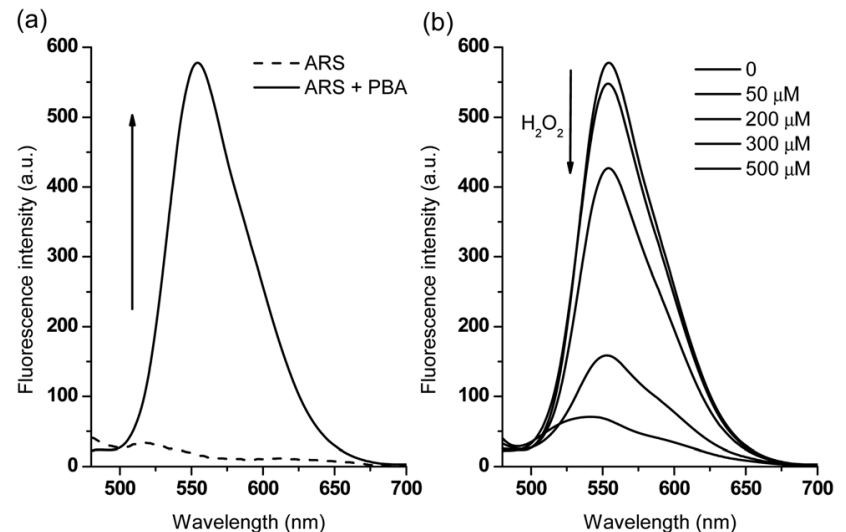

Fig. 2 Fluorescence spectra $\left(\lambda_{\mathrm{ex}}=460 \mathrm{~nm}\right)$ of ARS only $(50 \mu \mathrm{M})$, ARSPBA (ARS, $50 \mu \mathrm{M}$; PBA, $200 \mu \mathrm{M}, 15 \mathrm{~min}$ ) (a) and then addition of $\mathrm{H}_{2} \mathrm{O}_{2}$ $(50,200,300,500 \mu \mathrm{M})$, respectively for $60 \mathrm{~min}$ (b). The data was obtained in $1 / 15 \mathrm{M}$ PBS buffer with $2.0 \mathrm{mM} \mathrm{CTAB}$ solution at $25^{\circ} \mathrm{C}$.

Subsequently, we investigated the fluorescence sensing ability towards $\mathrm{H}_{2} \mathrm{O}_{2}$ in time and dose-dependent manner. Initially, a higher concentration of PBA $(600 \mu \mathrm{M})$ was used since it triggered a larger fluorescence increase $\left(F / F_{0}=38.5\right)$ in the presence of ARS $(50 \mu \mathrm{M}$, Fig. S2 $\dagger)$. However, from the timedependant curve (Fig. S3†) and dose-dependent curve (Fig. S4 $\dagger$ ), it was found that when using higher concentrations of PBA, in order to quench the fluorescence completely, a higher concentration of $\mathrm{H}_{2} \mathrm{O}_{2}$ (approximately $1 \mathrm{mM}$, quenching efficiency $F_{\mathrm{T}} / F_{0}=0.06$ ) was required over a long time period $(1 \mathrm{~h})$. This is attributed to the excess phenylboronic acid present in the system consuming significant amounts of $\mathrm{H}_{2} \mathrm{O}_{2}$. Therefore, for the sake of sensitivity, we reduced the concentration of PBA to $200 \mu \mathrm{M}$ in the sensing system. As can be seen from Fig. 2a, the fluorescence intensity of ARS (50 $\mu \mathrm{M})$ increased to $F / F_{0}=28.5$ in the presence of PBA $(200 \mu \mathrm{M})$, while only $500 \mu \mathrm{M} \mathrm{H}_{2} \mathrm{O}_{2}$ resulted in a dramatic decrease in fluorescence (quenching efficiency, $F_{\mathrm{T}} / F_{0}=0.12$ ) over $1 \mathrm{~h}$ (Fig. $2 \mathrm{~b}$ and $\mathrm{S} 5 \dagger$ ). Thus, in the case of using lower PBA concentrations with ARS, resulted in lower concentrations of $\mathrm{H}_{2} \mathrm{O}_{2}$ being required to release ARS and to produce large fluorescence changes.

\subsection{Electrochemical measurements with $\mathrm{H}_{2} \mathrm{O}_{2}$}

Finally, we also evaluated our sensing procedure using electrochemistry in order to better explain the mechanisms involved, square wave voltammetry (SWV) (only the homogeneous effects were evaluated as the electrode was polished before each scan). To the PBS buffer solution of ARS $(50 \mu \mathrm{M})$, PBA $(200 \mu \mathrm{M})$ was added to form the complex for further study. The oxidation signal of free ARS at an electrochemical potential of $0.375 \mathrm{~V}$ was remarkably decreased due to the hindered oxidation of ARS unit after its complexation with PBA (Fig. 3a).

The electrical effect on the system consisting of ARS-PBA was studied over time after addition of $\mathrm{H}_{2} \mathrm{O}_{2}(300 \mu \mathrm{M}$, Fig. 3b). We can see reappearance of the peak for the released ARS at $0.375 \mathrm{~V}$ and the generation of phenol, cleaved from PBA by 
(a)
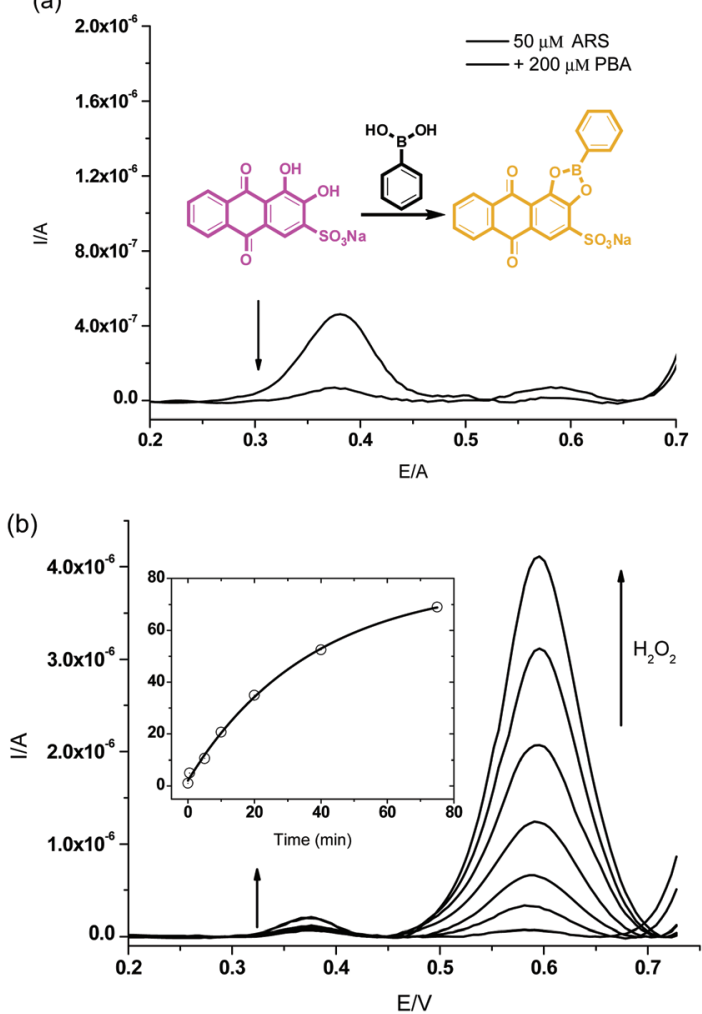

Fig. 3 Square wave voltammograms for (a) the ARS only $(50 \mu \mathrm{M})$, ARSPBA (ARS, $50 \mu \mathrm{M}$; PBA, $200 \mu \mathrm{M})$ (b) and then addition of $\mathrm{H}_{2} \mathrm{O}_{2}(300 \mu \mathrm{M}$, 0-75 min), Time-kinetics curve as embedded figure.

$\mathrm{H}_{2} \mathrm{O}_{2}$ was tracked using the signal at $0.585 \mathrm{~V}$. The oxidation process for ARS-PBA were enhanced over time (0-80 min) due to the reaction and hydrolysis of the intermediate. The inequality of ARS and phenol peaks is caused not only by the different electrochemical activity and mobility of these two molecules but also by subsequent boronic acid-diol, i.e. ARSPBA interactions. It has been already shown that the cleavage of PBA forming borate and phenol is accelerated by added diol. ${ }^{11}$ ARS acts in a catalytic manner as it is released from the cleaved complex and interacts with another PBA molecule facilitating its cleavage. It is important to note that slow cleavage of PBA occurs spontaneously and also contributes to the observed phenol signal.

\subsection{CTAB influence on sensitivity and selectivity}

The effect of CTAB on the binding of ARS with PBA and on the sensitivity of reaction with $\mathrm{H}_{2} \mathrm{O}_{2}$ was determined (Fig. S6 and $\mathrm{S} 7 \dagger)$. At various CTAB (1-20 mM) concentrations, fluorescence intensities of the ARS-PBA complex were enhanced due to a strengthening of the interactions (Fig. S6b $†$ ). Then we compared the emission intensity changes for the ARS-PBA complexes with different concentrations of CTAB using a constant $500 \mu \mathrm{M}$ of $\mathrm{H}_{2} \mathrm{O}_{2}$ (Fig. S7†). The ARS-PBA system with $1 \mathrm{mM}$ CTAB produced the biggest response toward $\mathrm{H}_{2} \mathrm{O}_{2}$ and further increases of CTAB concentrations reduced the $\mathrm{H}_{2} \mathrm{O}_{2}$ response up to $5 \mathrm{mM}$ after which the response remained constant (Fig. S7b $\dagger$ ).

We then evaluated the selectivity of the ARS-PBA system towards various ROS, Fig. S8-S10. $\dagger$ In the absence of CTAB, the complex of ARS-PBA produces a weak fluorescence and displayed fluorescence turn-off in the presence of ROS $\left({ }^{-} \mathrm{OCl}\right.$, $\mathrm{H}_{2} \mathrm{O}_{2}, \mathrm{ROO}^{\cdot},{ }^{-} \mathrm{O}_{2},{ }^{\circ} \mathrm{OH},{ }^{1} \mathrm{O}_{2}, 500 \mu \mathrm{M}$, respectively), with the following selectivity order: ${ }^{-} \mathrm{OCl}>\mathrm{H}_{2} \mathrm{O}_{2}>{ }^{\circ} \mathrm{OH}>{ }^{1} \mathrm{O}_{2}>\mathrm{ROO}^{\circ}=$ ${ }^{-} \mathrm{O}_{2}$. However, in the presence of $2 \mathrm{mM} \mathrm{CTAB}$, the ARS-PBA complex displayed a strong fluorescence and the following selectivity order towards ROS: ${ }^{\circ} \mathrm{OH}>\mathrm{H}_{2} \mathrm{O}_{2}>{ }^{-} \mathrm{OCl}>{ }^{-} \mathrm{O}_{2}>{ }^{1} \mathrm{O}_{2}>$ $\mathrm{ROO}^{\circ}$. The surprisingly high response to hydroxyl radical with CTAB is probably due to degradation of the surfactant. ${ }^{32}$ Whilst the reduced response towards hypochlorite can be ascribed to the micelle protecting the ARS-PBA complex from attack by the ROS.

In summary, CTAB is essential for facilitating ARS-PBA complex formation and therefore enhancing the fluorescence response towards ROS.

\section{Conclusion}

Using the assembly of phenylboronic acid with Alizarin Red S aided by CTAB, we have developed a chemosensor for the detection of $\mathrm{H}_{2} \mathrm{O}_{2}$ in aqueous media. We have analysed its behaviour towards $\mathrm{H}_{2} \mathrm{O}_{2}$ using colorimetric, fluorescence, and electrochemical techniques. The experimental observations demonstrate that the assembled RIA probe displays a visible colour change, on-off fluorescence response and turn-on electrochemical signal, for the sensing of $\mathrm{H}_{2} \mathrm{O}_{2}$. Indicating that our reaction-based indicator displacement assay (RIA) concept can provide a good platform as a new and rapid diagnostic assay for $\mathrm{H}_{2} \mathrm{O}_{2}$ and hydrogen peroxide-related environmental and physiological analysis in the future.

\section{Acknowledgements}

TDJ and XS are grateful for financial support from China Scholarship Council (CSC) and University of Bath Full Fees Scholarship. ACS and MLO thank the EPSRC for Studentships. The Catalysis And Sensing for our Environment (CASE) network is thanked for research exchange opportunities. KL is grateful for financial support from the Ministry of Education, Youth and Sports of the Czech Republic under the project CEITEC 2020 (LQ1601) and from the EU Seventh Framework Programme under the "Capacities" specific programme (Contract No. 286154 - SYLICA). TDJ Thanks SUST for a Guest Professorship.

\section{Notes and references}

1 L. J. Thénard, Annales de chimie et de physique, 2nd series, 1818, vol. 8, pp. 306-312. 
2 C. Tredwin, S. Naik, N. Lewis and C. Scully, Br. Dent. J., 2006, 200, 371-376.

3 B. E. Watt, A. T. Proudfoot and J. A. Vale, Toxicol. Rev., 2004, 23, 51-57.

4 M. Giorgio, M. Trinei, E. Migliaccio and P. G. Pelicci, Nat. Rev. Mol. Cell Biol., 2007, 8, 722-728.

5 J. P. Fruehauf and F. L. Meyskens, Clin. Cancer Res., 2007, 13, 789-794.

6 M. P. Mattson, Nature, 2004, 430, 631-639.

7 H. Ohshima, M. Tatemichi and T. Sawa, Arch. Biochem. Biophys., 2003, 417, 3-11.

8 E. Galbraith and T. D. James, Chem. Soc. Rev., 2010, 39, 3831-3842.

9 R. Nishiyabu, Y. Kubo, T. D. James and J. S. Fossey, Chem. Commun., 2012, 47, 1106-1123.

10 S. D. Bull, M. G. Davidson, J. M. van den Elsen, J. S. Fossey, A. T. Jenkins, Y. B. Jiang, Y. Kubo, F. Marken, K. Sakurai, J. Zhao and T. D. James, Acc. Chem. Res., 2013, 46, 312-326.

11 X. Sun, S.-Y. Xu, S. E. Flower, J. S. Fossey, X. Qian and T. D. James, Chem. Commun., 2013, 49, 8311-8313.

12 X. Sun, Q. Xu, G. Kim, S. E. Flower, J. P. Lowe, J. Yoon, J. S. Fossey, X. Qian, S. D. Bull and T. D. James, Chem. Sci., 2014, 5, 3368.

13 M. C. Y. Chang, A. Pralle, E. Y. Isacoff and C. J. Chang, J. Am. Chem. Soc., 2004, 126, 15392-15393.

14 A. E. Albers, V. S. Okreglak and C. J. Chang, J. Am. Chem. Soc., 2006, 128, 9640-9641.

15 E. W. Miller, O. Tulyathan, E. Y. Isacoff and C. J. Chang, Nat. Chem. Biol., 2007, 3, 263-267.

16 D. Srikun, E. W. Miller, D. W. Domaille and C. J. Chang, J. Am. Chem. Soc., 2008, 130, 4596-4597.

17 G. C. Van de Bittner, E. A. Dubikovskaya, C. R. Bertozzi and C. J. Chang, Proc. Natl. Acad. Sci. U. S. A, 2010, 107, 2131621321.
18 D. Srikun, A. E. Albers, C. I. Nam, A. T. Iavarone and C. J. Chang, J. Am. Chem. Soc., 2010, 132, 4455-4465.

19 B. C. Dickinson, C. Huynh and C. J. Chang, J. Am. Chem. Soc., 2010, 132, 5906-5915.

20 E. W. Miller, A. E. Albers, A. Pralle, E. Y. Isacoff and C. J. Chang, J. Am. Chem. Soc., 2005, 127, 16652-16659.

21 G. C. Van de Bittner, C. R. Bertozzi and C. J. Chang, J. Am. Chem. Soc., 2013, 135, 1783-1795.

22 B. C. Dickinson, Y. Tang, Z. Chang and C. J. Chang, Chem. Biol., 2011, 18, 943-948.

23 A. R. Lippert, G. C. Van de Bittner and C. J. Chang, Acc. Chem. Res., 2011, 44, 793-804.

24 G. Springsteen and B. Wang, Chem. Commun., 2001, 16081609.

25 C. Cannizzo, S. Amigoni-Gerbier and C. Larpent, Polymer, 2005, 46, 1269-1276.

26 D. K. Palit, H. Pal, T. Mukherjee and J. P. Mittal, J. Chem. Soc., Faraday Trans., 1990, 86, 3861-3869.

27 W. M. J. Ma, M. P. Pereira Morais, F. D’Hooge, J. M. H. van den Elsen, J. P. L. Cox, T. D. James and J. S. Fossey, Chem. Commun., 2009, 532-534.

28 K. Ngamdee, T. Noipa, S. Martwiset, T. Tuntulani and W. Ngeontae, Sens. Actuators, B, 2011, 160, 129-138.

29 X. L. Sun, K. Lacina, E. C. Ramsamy, S. E. Flower, J. S. Fossey, X. H. Qian, E. V. Anslyn, S. D. Bull and T. D. James, Chem. Sci., 2015, 6, 2963-2967.

30 Z. Xu, S. K. Kim, S. J. Han, C. Lee, G. Kociok-Kohn, T. D. James and J. Yoon, Eur. J. Org. Chem., 2009, 2009, 3058-3065.

31 Y. Kubo, M. Yamamoto, M. Ikeda, M. Takeuchi, S. Shinkai, S. Yamaguchi and K. Tamao, Angew. Chem., Int. Ed., 2003, 42, 2036-2040.

32 O. Horváth and R. Huszánk, Photochem. Photobiol. Sci., 2003, 2, 960-966. 